\title{
Genomics of Maize Stover Yield and Saccharification Efficiency Using a Multi-Parent Advanced Generation Intercross (MAGIC) Population
}

\section{Ana Lopez-Malvar ( $\square$ alopezmalvar@uvigo.es )}

Universidade de Vigo Facultad de Biologia https://orcid.org/0000-0001-5079-7132

\author{
A Butron \\ Mision Biologica de Galicia \\ R Malvar \\ Mision Biologica de Galicia \\ LD Gomez \\ CNAP, Department of Biology, University of York

\section{Faas} \\ CNAP, Department of Biology, University of York
}

\section{S McQueen-Mason}

CNAP, Department of Biology, University of York

\section{P Revilla}

Mision Biologica de Galicia

\section{DJ Figueroa-Garrido}

Universidade de Vigo Facultad de Biologia

\section{R Santiago}

Universidade de Vigo Facultad de Biologia

\section{Research}

Keywords: Association mapping, Zea mays, saccharification, MAGIC, biofuel, lignocellulosic biomass

Posted Date: March 12th, 2020

DOI: https://doi.org/10.21203/rs.3.rs-16878/v1

License: () (i) This work is licensed under a Creative Commons Attribution 4.0 International License. Read Full License 


\section{Abstract}

Background: Cellulosic ethanol derived from fast growing C4 grasses could become an alternative to finite fossil fuels. With the potential to generate a major source of lignocellulosic biomass, maize has gained importance as an outstanding model plant for studying the complex cell wall network, and as a model to optimize crop breeding strategies in bioenergy grasses. A genome-wide association study was conducted using a subset of 408 Recombinant Inbred Lines (RILs) from a Multiparent-Advanced Intercross (MAGIC) Population in order to identify single nucleotide polymorphisms (SNPs) associated with yield and saccharification efficiency of maize stover.

Results: We identified 4 SNPs significantly associated with stover yield that corresponded to 4 QTL, and 16 SNPs significantly associated with saccharification efficiency, that could be clustered into 5 QTL. Markers linked to these QTL could be used in markerassisted selection programs to improve ethanol production. In addition, we have pointed out genes that contain the significant SNPs or are physically close to them.

Conclusions: Genes involved in nitrogen assimilation, organ growth, and stress tolerance could be good candidates attending to QTLs for stover yield. On the other hand, for saccharification efficiency we highlight genes implicated in biomass degradation, transcriptional control of monolignol biosynthesis, and lignin polymerization as probable candidate genes in the QTLs involved.

\section{Background}

In a scenario of global growth, depletion of natural resources and climate change the economic and environmental consequences of reliance in finite fossil biofuels has become a global concern. This situation has driven to exhaustive scientific research in order to find sustainable energetic alternatives. Cellulosic ethanol derived from fast growing $\mathrm{C} 4$ crops has become one of the preferred choice due to their high biomass yields, broad geographic adaptation, carbon sequestration and nutrient utilization $(1,2)$

With the potential to generate a major source of lignocellulosic biomass, maize has been postulated as a model for understanding the complex cell wall architecture, and to optimize crop breeding strategies in bioenergy grasses. Maize stover, the residue left after harvesting the grain, is the largest readily available lignocellulosic feedstock $(1,3-6)$

Lignocellulosic ethanol (second generation biofuel) from maize stover is composed of $33.1 \%$ hemicellulose, $39.4 \%$ cellulose, and $14.9 \%$ lignin $(7,8)$. The conversion of lignocellulosic biomass to ethanol is a three step process that: (i) a pre-treatment stage, followed by the (ii) hydrolytic degradation of carbohydrates to the constituent sugar monomers (saccharification), and the (iii) final fermentation of the free sugars to ethanol (9).

The key factor in this process is the stover recalcitrance to deconstruction, conferred by the composition and organization of the cell wall. Maize cell walls are mainly composed of cellulose microfibrils embedded in a matrix of hemicelluloses, lignin and to a lesser extent, pectins, proteins and phenolic compounds (mainly hydroxcinnamates) (10). This strong assemblage provides not only structural support and rigidity to the cell, but also resistance to biotic and abiotic stresses (11). The framework of hemicellulose and lignin closely interconnected with cellulose, prevents the action of hydrolytic enzymes reducing the degradability of carbohydrates. The degree of lignification and the polysaccharides crosslinking by diferulates, as well as cellulose crystallinity, contribute to the recalcitrance of lignocellulosic feedstock. This recalcitrance means a greater expense in pre-treatments and high enzyme inputs, which is translated in a greater economic cost. Therefore, reduction of the cell wall recalcitrance is expected to improve saccharification efficiency $(12,13)$.

It should be noted that the ability to produce ethanol depends on the genotype and on the applied pre-treatment. Therefore, to look for differences for ethanol production among genotypes, it is essential to choose the appropriate treatment for the tissue under study. Among a number of pre-treatments that could be used, alkaline pre-treatment has been suggested as the most appropriate for maize stover and other herbaceous plants $(14,15)$. The cell walls of gramineous monocots are known to contain alkali-labile ferulate ester cross-links within the hemicellulose and thereafter cross-linked with lignin $(16,17)$, as well as high phenolic hydroxyl contents in their lignins, resulting in increased alkali solubility (18). As a consequence, mild alkali pre-treatment of grasses can be employed for both fractionating biomass and generating pre-treated biomass that is highly amenable to enzymatic hydrolysis $(15,19)$. The optimisation and improvement of stover biofuel production should be focused on stover yields (expressed as tonnes of dry plant material per unit of land area) as well as on the stover quality under a specific pre-treatment. 
Mapping QTLs and identifying genes underlying stover quality and quantity are important stages in order to optimize selection programs for upgrading the biofuel production. Maize genetic variation for saccharification efficiency has been detected $(20,21)$ and several linkage mapping studies have been conducted to find QTLs for saccharification efficiency (22-24). Furthermore, Trunztler et al. (25) performed a metaQTL analysis that included several QTL mapping studies for digestibility and cell-wall components and found 27 saccharification-related QTLs. Lorenzana et al. (24) evaluated crosses of 223 maize recombinant inbred lines from B73 × Mo17 (IBM population) for cell wall composition and glucose release after acid pre-treatment and enzymatic hydrolysis and identified 10 QTLs for sugar release, 5 of them co-localizing with QTLs for lignin content. Also, in the IBM population, Penning et al. (26) found 4 QTLs for saccharification efficiency, measured as glucose or xylose releases after steam explosion, but none of them overlapped with QTLs for lignin. The differences in the results found in both studies may be dependent on the pre-treatment chemistry and/or the genotype response to pre-treatment and hydrolysis. Lorenzana et al. (24) measured the sugar release after dilute acid/high temperature pretreatment. This method uses strong acids to hydrolyse the hemicellulosic fraction of the biomass, resulting in a more effective enzymatic hydrolysis (27-29), whereas in Penning et al. (26) samples were subjected to steam explosion at $180^{\circ} \mathrm{C}$.

However, the explored genetic variation for saccharification efficiency has been low because the studies mentioned above were performed using just bi-parental populations and thereby the resolution of the detected QTLs was low. One of the most robust techniques for high resolution mapping of QTLs is Genome-Wide Association Mapping using diversity panels. This technique has been extensively used in maize to identify significant associations with yield and agronomic traits (30), biotic and abiotic resistance $(31,32)$, cell wall components (33-35) and lignin abundance and sugar yield (26). However, association studies using diversity panels could still have a limited power to detect QTLs due to the small effect and/or low frequency (rare alleles) of some genetic variants, so many undetected rare alleles could be loss for breeding purposes even having major effects (36-38). Therefore, results from QTL mapping in Multi-Parent Advanced Generation Inter-Cross (MAGIC) populations could be complementary to results from bi-parental populations and association mapping panels because several alleles can be simultaneously studied but none of them would be in low frequency (39-41). In addition, even though QTL resolution in MAGIC populations is not as high as in diversity panel's, MAGIC populations present a known underlying structure that better prevents from false positive associations than unstructured populations.

We developed a MAGIC population using eight temperate maize inbred lines of diverse genetic origin, where the eight founders have a common characteristic: the lack of Stiff Stalk Materials in their pedigrees $(39,41)$. Six founders were directly obtained from different open-pollinated varieties from Spain, Italy, and France, while two inbred lines derived from North American materials. New inbreds developed from this MAGIC population could have practical interest for breeders as they are expected to express high heterosis when crossed to inbreds from the Stiff Stalk heterotic group. In the present study we identified genomic regions and genes associated with saccharification efficiency and stover yield using this MAGIC population. Results provide a better understanding of the genetic factors that can modulate these traits and the molecular tools to be used in breeding programs for increasing stover production and saccharification efficiency.

\section{Results}

\section{Means and Analysis of Variance}

The analyses of variance showed that differences among check inbreds were significant for stover yield but not for saccharification efficiency. However, RIL means differed significantly for both traits (data not shown). Means and ranks for the traits under study are detailed in Table 1. Data for EP43 and PB130 was not available, both founders of the MAGIC population, was not available either because the seeds did not germinate or either there were not enough plants in the plot. 
Table 1

Means ${ }^{1}$ and ranks for the RILs of the maize MAGIC population, and mean comparisons of the check inbreds for saccharification efficiency and stover yield.

\begin{tabular}{|lll|}
\hline & $\begin{array}{l}\text { Saccharification } \\
\text { (nmol/mg material.hour) }\end{array}$ & $\begin{array}{l}\text { Stover Yield } \\
(\mathrm{Mg} / \mathrm{ha})\end{array}$ \\
\hline RILs & $138.7 \pm 0.571$ & $3.328 \pm 0.089$ \\
\hline Means & $113.2-162.8$ & $0.354-8.608$ \\
\hline Rank & $138.4 \pm 3.124^{\mathrm{a}}$ & \\
\hline Checks & $137.3 \pm 3.769^{\mathrm{a}}$ & $2.098 \pm 0.373^{\mathrm{a}}$ \\
\hline A509 & $132.4 \pm 2.589^{\mathrm{a}}$ & $1.598 \pm 0.450^{\mathrm{a}}$ \\
\hline EP125 & $134.5 \pm 6.434^{\mathrm{a}}$ & $5.815 \pm 0.309^{\mathrm{b}}$ \\
\hline EP17 & $143.1 \pm 4.017^{\mathrm{a}}$ & $1.680 \pm 0.769^{\mathrm{a}}$ \\
\hline EP53 & $102.84 \pm 17.04^{\mathrm{a}}$ & $2.671 \pm 0.333^{\mathrm{a}}$ \\
\hline EP86 & $133.9 \pm 2.786^{\mathrm{a}}$ & $2.789 \pm 0.398^{\mathrm{a}}$ \\
\hline F473 & $172.1 \pm 14.16^{\mathrm{a}}$ & $2.697 \pm 0.480^{\mathrm{a}}$ \\
\hline EP80 & & $2.015 \pm 0.340^{\mathrm{b}}$ \\
\hline EC212 & & \\
\hline 1 Means followed by the same letter within the same column are not significantly different $(\mathrm{P}<0.05)$ \\
\hline
\end{tabular}

\section{Association Analysis}

We carried out association analysis to determine genomic regions that modify stover yield and saccharification efficiency. A marker was considered significantly associated with a trait at $p$ values less than $2.42 \times 10^{-5}(-\log 10(p$-value $)=4.6)$. We considered a $+/-700 \mathrm{kbp}$ region as confident SNP interval and two SNPs were included in the same QTL when their confident intervals overlapped. We identified 4 SNPs associated with 4 stover yield QTL (qStoverYield_1_1, qStoverYield_3_1, qStoverYield_3_2 and qStoverYield_5_1), and 16 SNPs that were associated with 5 saccharification efficiency QTLs (qSACC_1_1, qSACC_1_2, qSACC_2_1, qSACC_6_1 and qSACC_10_1). SNPs and QTLs are detailed in Table 2. Minor frequency alleles generally decreased stover yield but minor and major frequency alleles contributed almost equally to increased saccharification efficiency. The percentages of phenotypic variance explained by each significant SNP ranged from 5 to $9 \%$. The significant SNPs found in the current study were distributed in bins $1.05,3.05$ and 5.00 for stover yield and in 1.05, 2.06, 6.07 and 10.07 for saccharification efficiency (Table 2). 
Table 2

SNPs and QTL significantly associated with saccharification (SACC) and stover yield, including SNP's chromosome, bin and position within chromosome, allelic variants and additive effect for the SNP, proportion of total variance explained by the SNP and p-value for

the association between the SNP and the phenotype.

\begin{tabular}{|c|c|c|c|c|c|c|c|c|c|c|}
\hline Trait ${ }^{\mathrm{a}}$ & $\mathrm{QTL}^{\mathrm{b}}$ & SNP ${ }^{c}$ & Position & $\mathrm{Chr}^{\mathrm{d}}$ & $\operatorname{Bin}^{e}$ & Alleles ${ }^{f}$ & (No) ${ }^{g}$ & $\begin{array}{l}\text { Additive } \\
\text { Effect }^{\mathrm{h}}\end{array}$ & $\begin{array}{l}P \text { - } \\
\text { value }\end{array}$ & $\mathbf{R}^{2 i}$ \\
\hline $\begin{array}{l}\text { Stover } \\
\text { Yield }\end{array}$ & qStoverYield_1_1 & S1_82702920 & 82702920 & 1 & 1.05 & $\mathrm{G} / \mathrm{A}$ & $39 / 310$ & 0.58 & $\begin{array}{l}1.86 \mathrm{E}- \\
05\end{array}$ & 0.054 \\
\hline $\begin{array}{l}\text { Stover } \\
\text { Yield }\end{array}$ & qStoverYield_3_1 & S3_135911317 & 135911317 & 3 & 3.05 & $\mathrm{~T} / \mathrm{C}$ & $77 / 204$ & 0.50 & $\begin{array}{l}2.21 \mathrm{E}- \\
05\end{array}$ & 0.073 \\
\hline $\begin{array}{l}\text { Stover } \\
\text { Yield }\end{array}$ & qStoverYield_3_2 & S3_143233104 & 143233104 & 3 & 3.05 & $\mathrm{G} / \mathrm{C}$ & $62 / 248$ & 0.53 & $\begin{array}{l}8.47 \mathrm{E}- \\
06\end{array}$ & 0.070 \\
\hline $\begin{array}{l}\text { Stover } \\
\text { Yield }\end{array}$ & qStoverYield_5_1 & S5_2334078 & 2334078 & 5 & 5.00 & $A / G$ & $15 / 255$ & 0.91 & $\begin{array}{l}8.35 \mathrm{E}- \\
06\end{array}$ & 0.070 \\
\hline SACC & qSACC_1_1 & S1_139597124 & 139597124 & 1 & 1.05 & $\mathrm{G} / \mathrm{C}$ & $41 / 317$ & 3.79 & $\begin{array}{l}1.94 \mathrm{E}- \\
05\end{array}$ & 0.053 \\
\hline SACC & qSACC_1_2 & S1_147891886 & 147891886 & 1 & 1.05 & $A / G$ & $36 / 274$ & 4.00 & $\begin{array}{l}2.29 \mathrm{E}- \\
05\end{array}$ & 0.062 \\
\hline SACC & qSACC_1_2 & S1_148230447 & 148230447 & 1 & 1.05 & $\mathrm{G} / \mathrm{A}$ & $27 / 314$ & 4.50 & $\begin{array}{l}2.28 \mathrm{E}- \\
05\end{array}$ & 0.056 \\
\hline SACC & qSACC_1_2 & S1_148515382 & 148515382 & 1 & 1.05 & $A / G$ & $44 / 265$ & 3.72 & $\begin{array}{l}1.85 \mathrm{E}- \\
05\end{array}$ & 0.060 \\
\hline SACC & qSACC_1_2 & S1_148515456 & 148515456 & 1 & 1.05 & $\mathrm{~T} / \mathrm{G}$ & $55 / 165$ & 3.63 & $\begin{array}{l}2.19 \mathrm{E}- \\
05\end{array}$ & 0.090 \\
\hline SACC & qSACC_2_1 & S2_184967723 & 184967723 & 2 & 2.06 & $\mathrm{C} / \mathrm{A}$ & $55 / 256$ & 2.67 & $\begin{array}{l}2.31 \mathrm{E}- \\
05\end{array}$ & 0.058 \\
\hline SACC & qSACC_6_1 & S6_163421359 & 163421359 & 6 & 6.07 & $\mathrm{G} / \mathrm{C}$ & $243 / 63$ & 3.02 & $\begin{array}{l}6.26 \mathrm{E}- \\
06\end{array}$ & 0.073 \\
\hline SACC & qSACC_6_1 & S6_163628712 & 163628712 & 6 & 6.07 & $\mathrm{~T} / \mathrm{A}$ & $102 / 105$ & 2.90 & $\begin{array}{l}4.77 \mathrm{E}- \\
06\end{array}$ & 0.087 \\
\hline SACC & qSACC_6_1 & S6_163629442 & 163629442 & 6 & 6.07 & $\mathrm{~A} / \mathrm{G}$ & $110 / 243$ & 2.92 & $\begin{array}{l}1.29 \mathrm{E}- \\
05\end{array}$ & 0.054 \\
\hline SACC & qSACC_6_1 & S6_163631485 & 163631485 & 6 & 6.07 & $\mathrm{G} / \mathrm{A}$ & $132 / 127$ & 3.05 & $\begin{array}{l}5.87 \mathrm{E}- \\
06\end{array}$ & 0.080 \\
\hline SACC & qSACC_6_1 & S6_163830244 & 163830244 & 6 & 6.07 & $\mathrm{~T} / \mathrm{C}$ & $119 / 116$ & 0.58 & $\begin{array}{l}5.06 \mathrm{E}- \\
06\end{array}$ & 0.075 \\
\hline SACC & qSACC_6_1 & S6_163830262 & 163830262 & 6 & 6.07 & $\mathrm{C} / \mathrm{T}$ & $197 / 88$ & 0.50 & $\begin{array}{l}1.78 \mathrm{E}- \\
05\end{array}$ & 0.065 \\
\hline SACC & qSACC_6_1 & S6_163930363 & 163930363 & 6 & 6.07 & $\mathrm{C} / \mathrm{A}$ & $80 / 230$ & 0.53 & $\begin{array}{l}9.92 \mathrm{E}- \\
06\end{array}$ & 0.065 \\
\hline SACC & qSACC_10_1 & S10_147845987 & 147845987 & 10 & 10.07 & $A / G$ & $215 / 39$ & 4.14 & $\begin{array}{l}8.29 \mathrm{E}- \\
06\end{array}$ & 0.073 \\
\hline SACC & qSACC_10_1 & S10_147845988 & 147845988 & 10 & 10.07 & $\mathrm{G} / \mathrm{T}$ & $215 / 39$ & 4.14 & $\begin{array}{l}8.29 \mathrm{E}- \\
06\end{array}$ & 0.073 \\
\hline SACC & qSACC_10_1 & S10_147845989 & 147845989 & 10 & 10.07 & $\mathrm{G} / \mathrm{T}$ & $215 / 39$ & 4.14 & $\begin{array}{l}8.29 \mathrm{E}- \\
06\end{array}$ & 0.073 \\
\hline \multicolumn{11}{|c|}{ a: SACC: Saccharification efficiency } \\
\hline
\end{tabular}




\begin{tabular}{|c|c|c|c|c|c|c|c|c|c|}
\hline Trait $^{a}$ & $Q_{T L}^{b}$ & $\mathrm{SNP}^{\mathrm{c}}$ & Position & $\mathrm{Chr}^{\mathrm{d}}$ & $\operatorname{Bin}^{e}$ & Alleles $^{f}$ & $(\mathrm{No})^{g}$ & $\begin{array}{l}\text { Additive } \\
\text { Effect }^{\mathrm{h}}\end{array}$ & $\begin{array}{l}\mathrm{P} \text { - } \\
\text { value }\end{array}$ \\
\hline
\end{tabular}

c: The number before the underscores indicates the chromosome number and the number after the underscore indicates the physical position in bp within the chromosome.

\section{d: Chromosome}

e: A bin is the interval that includes all loci from the leftmost or top Core Marker to the next Core Marker. The genetic maps are divided into 100 segments of approximately 20 centiMorgans designated with the chromosome number followed by a two-digit decimal (89)

$\mathrm{f}$ : The letter before the diagonal is the nucleotide with the largest value; and the letter after the diagonal is the nucleotide with the smallest value.

g: No = Number of inbred lines homozygous for a determined allelic variant, the number before the diagonal represents the number of homozygous with the largest mean value; and the number after the diagonal the number of homozygous with the smallest mean value.

h: Additive effect: the additive effect was calculated as half the difference between the mean of the homozygous for the allele with the largest value and the mean of the homozygous for the allele with the smallest value.

i: Phenotypic variance explained by each marker.

\section{Candidate Gene Selection}

The genes containing or physically close to SNPs significantly associated with traits were identified and characterized according to the maize B73 reference genome assembly, version 4 (Supplementary Table 1). Analyses of $+/$ - 700kbp regions surrounding significant SNPs resulted in the identification of the genes listed in Supplementary table 1.

Based on the annotated functions of the identified genes, we highlight six genes as the most probable candidates for being behind the four QTLs involved in stover yield: glutathione S-transferase (Zm00001d041772), glutamate synthase (Zm00001d029732), Zar9-

ARGOS9 (Zm00001d041774), L-ascrobate peroxidase 2 cytosolic (Zm00001d041939), GRAS5 tf (Zm00001d041919) and anthranilate synthase (Zm00001d012925). Similarly, seven genes are proposed as candidate genes for saccharification efficiency QTLs: two MYB transcription factors, MYB 100 (Zm00001d030644) and MYB 130 (Zm00001d038930), hydroxycinnamoyl transferase (HCT) (Zm00001d030542), Gibbellerin 2-oxidase (Zm00001d038996), galacturonosyl transferase (Zm00001d038947) and two pectinesterase (Zm00001d030622, Zm00001d030643) genes (Table 3). 
Table 3

List of candidate genes for the QTL for saccharification efficiency and stover yield found in the MAGIC population. Candidate genes were selected among all genes found in the +-700.000 bp QTL intervals.

\begin{tabular}{|c|c|c|c|c|c|c|}
\hline Trait $^{a}$ & $Q_{T L}^{b}$ & SNPc & Chrec $^{c}$ & Bin $^{d}$ & Gene $^{f}$ & Gene annotationg \\
\hline $\begin{array}{l}\text { Stover } \\
\text { Yield }\end{array}$ & $\begin{array}{l}\text { qStover } \\
\text { Yield_1_1 }\end{array}$ & S1_82702920 & 1 & 1.05 & Zm00001d029732 & glutamate synthase 1 [NADH], chloroplastic \\
\hline $\begin{array}{l}\text { Stover } \\
\text { Yield }\end{array}$ & $\begin{array}{l}\text { qStover } \\
\text { Yield_3_1 }\end{array}$ & S3_135911317 & 3 & 3.05 & $\begin{array}{l}\text { Zm00001d041748 } \\
\text { Zm00001d041750 }\end{array}$ & $\begin{array}{l}\text { glutathione transferase } 18 \\
\text { Zea mays ARGOS9 }\end{array}$ \\
\hline $\begin{array}{l}\text { Stover } \\
\text { Yield }\end{array}$ & $\begin{array}{l}\text { qStove } \\
\text { rYield_3_2 }\end{array}$ & S3_143233104 & 3 & 3.05 & $\begin{array}{l}\text { Zm00001d041939 } \\
\text { Zm00001d041919 }\end{array}$ & $\begin{array}{l}\text { L-ascorbateperoxidase } 2 \\
\text { GRAS-transcription factor } 5\end{array}$ \\
\hline $\begin{array}{l}\text { Stover } \\
\text { Yield }\end{array}$ & $\begin{array}{l}\text { qStover } \\
\text { Yield_5_1 }\end{array}$ & S5_2334078 & 5 & 5 & Zm00001d012925 & $\begin{array}{l}\text { anthranilate synthase } \\
\text { alpha subunit } 1 \text {, chloroplastic }\end{array}$ \\
\hline SACC & qSACC_1_1 & S1_139597124 & 1 & 1.05 & Zm00001d030523 & hydroxycinnamoyltransferase 4 \\
\hline SACC & qSACC_1_2 & $\begin{array}{l}\text { S1_147891886 } \\
\text { S1_148230447 } \\
\text { S1_148515382 }\end{array}$ & 1 & 1.05 & $\begin{array}{l}Z m 00001 d 030617 \\
Z m 00001 d 030618 \\
Z m 00001 d 030620\end{array}$ & $\begin{array}{l}\text { pectinesterase } 3 \\
\text { pectinesterase } 48 \\
\text { MYB-transcription factor } 100\end{array}$ \\
\hline SACC & qSACC_6_1 & $\begin{array}{l}\text { S6_163421359 } \\
\text { S6_163628712 } \\
\text { S6_163629442 } \\
\text { S6_163631485 } \\
\text { S6_163830244 } \\
\text { S6_163830262 } \\
\text { S6_163930363 }\end{array}$ & 6 & 6.07 & $\begin{array}{l}Z m 00001 d 005863 \\
Z m 00001 d 005865 \\
Z m 00001 d 038966\end{array}$ & $\begin{array}{l}\text { MYB-transcription factor } 130 \\
\text { galacturonosyltransferase-like } 9 \\
\text { gibberellin 2-oxidase8 }\end{array}$ \\
\hline SACC & qSACC_10_1 & S10_147845989 & 10 & 10.07 & & \\
\hline \multicolumn{7}{|c|}{ a: SACC: Saccharification efficiency } \\
\hline \multicolumn{7}{|c|}{$\begin{array}{l}\text { b: The number before the underscores indicates the chromosome and the number after the underscores indicates the QTL within } \\
\text { the chromosome. }\end{array}$} \\
\hline \multicolumn{7}{|c|}{$\begin{array}{l}\text { c: The number before the underscores indicates the chromosome and the number after the underscores indicates the marker } \\
\text { position in the B73 Reference Genome version } 2 \text {. }\end{array}$} \\
\hline \multicolumn{7}{|c|}{ e: Chr: Chromosome. } \\
\hline \multicolumn{7}{|c|}{$\begin{array}{l}\text { f: A bin is the interval that includes all loci from the leftmost or top Core Marker to the next Core Marker. The genetic maps are } \\
\text { divided into } 100 \text { segments of approximately } 20 \text { centiMorgans designated with the chromosome number followed by a two-digit } \\
\text { decimal. }\end{array}$} \\
\hline \multicolumn{7}{|c|}{ g: Name of the gene in B73 Reference Genome version 4} \\
\hline \multicolumn{7}{|c|}{ h: Gene annotation according to Zm-B73 reference form Gramene. } \\
\hline
\end{tabular}

The genes considered as candidates for improving stover yield are involved in detoxification of reactive oxygen species (glutathiones Stransferase, L-ascorbate peroxidase), nitrogen assimilation (glutamate synthase), plant and organ growth and development (Zar9ARG0S9, GRAS5 tf), and auxin homeostasis (anthranilate synthase). In the case of saccharification efficiency, HCT is a key enzyme in the synthesis of lignin subunits and MYB transcription factors are in charge of the control of the genes involved in monolignol biosynthesis and polymerization. Among the other genes found, pectinesterases are involved in cell wall degradation, galactorunosyl transferase is involved in pectin biosynthesis and Gibbellerin 2-oxidase is related with reduced cell wall recalcitrance trough the deactivation of the gibberellic acid.

\section{Discussion}

An optimisation of biofuel feedstock can be achieved using plant breeding for increasing stover yield and quality. Stover quality is associated to the composition of the cell wall and the potential for saccharification (42). Only one of the QTLs found was significantly associated with saccharification efficiency in this study, and coincides in the same bin than those previously described for glucose yield (24). With respect to other studies, we describe new regions related to saccharification efficiency in bins $1.05,6.07$ and 10.07. According 
to the above mentioned co-localizations we should take into account that we are referring to QTLs detected at the bin scale and QTLs detected in bi-parental populations corresponds sometimes to a different vegetal material or pre-treatment method.

Genetic markers and genes associated with these traits can allow the establishment of breeding programs based on genomic selection or marker-assisted selection for increasing stover and saccharification yields to avoid heavy and expensive field evaluations and laboratory assays.

In the next paragraphs, we support the reasons for the proposed genes involved in plant development, growth, and assimilation of nutrients as probable candidate genes for the QTL involved in stover yield.

Nitrogen supply is one of the major factors limiting growth and productivity in crops, affecting both grain and stover yields. Therefore, we propose glutamate synthase 1 (Zm00001d029732) gene as candidate gene for the QTL qStoverYield_1_1 because the enzyme glutamate synthase is essential for ammonia assimilation in plants and has been proposed as a key target enzyme to improve nitrogen assimilation efficiency. Chichkova et al. (43) found a direct relation between this gene and variability for biomass as they observed increases in shoot weight and shoot total nitrogen and carbon contents in tobacco transgenic plants overexpressing NADH-glutamate synthase.

In addition, stover yield is determined by plant development and growth, processes that are greatly limited by biotic and abiotic stresses $(1,44)$. Authors, have reported that biomass yield increase can be achieved through enhancing mechanisms of stress tolerance (4547). As generation of reactive oxygen species (ROS) occurs at stress conditions, plant mechanisms to protect from ROS damage could contribute to enhanced tolerance to stress because oxidative stress has a negative effect on biomass and plant fitness (48).

Consequently, glutathione S-transferase (GST) genes that lie within the confidence intervals of QTLs for stover yield such as Zm00001d041772 which is located within qStoverYield_3_1 QTL could be highlighted as candidate genes because GST contribute to minimise ROS species (49). In the same way, for qStoverYield_3_2 we also spot as candidate the L-ascorbate peroxidase 2 gene (Zm00001d041939), involved in ascorbate-glutathione cycle and detoxification of hydrogen peroxide (50).

Another gene can be proposed as candidate gene for QTL qStoverYield_3_1, the Zar9 (Zm00001d041774), because it belongs to the Auxin-Regulated Genes involved in Organ Size (ARGOS) family of genes, that controls plant growth and organ size and have been assigned as key factor determining yield (51-53). Guo et al. (54) tested the effects of the maize overexpression of a Zar gene and found increased stalk, ear, and total dry biomasses, and leaf area. Also, the GRAS gene family plays a crucial role in diverse plant growth and development processes by being involved in gibberellin signalling. Within the confidence interval of qStoverYield_3_2, we highlight a gene encoding a GRAS tf as possible candidate for this QTL.

For the QTL qStoverYield_5_1, we highlight the gene (Zm00001d012925) that codifies for the a- subunit of an anthranilate synthase, the first enzyme in the tryptophan biosynthesis pathway, that has been suggested as a broader regulator in auxin production (55). Lu et al. (56) linked polymorphisms at a anthranilate synthase gene in rice to variability for yield; meanwhile higher accumulation of anthranilate synthase a-subunit in transgenic poplars could result in enhanced growth through the regulation of auxin biosynthesis (57).

Regarding saccharification efficiency, among the genes found within the confidence interval of each QTL, and based on previous knowledge, we can point out those involved in the phenylpropanoid pathway, especially in monolignol biosynthesis and polymerization, and the ones involved in cell wall deconstruction, and recalcitrance. Biomass hydrolysis is a key factor in lignocellulosic deconstruction and the complex polysaccharide matrix in the cell wall limits the accessibility to cellulose conferring recalcitrance to the whole structure and reducing saccharification efficiency $(1,3)$. Despite its low abundance in maize stems and leaves, pectins play a role in limiting saccharification efficiency $(58,59)$ so genes involved in pectin biosynthesis could be good candidates for saccharification efficiency QTLs. That is the case of the gene Zm00001d038947 (within qSACC_6_1 QTL), a galacturonosyl transferase involved in biosynthesis of homogalacturan $(\mathrm{HG})$ which is the main pectic polysaccharide and is involved in cell adhesion and cell wall plasticity (60). Downregulation of enzymes involved in HG biosynthesis modifies pectin organization and composition; leading to a significant reduction in cell wall cross-linking, and recalcitrance to pre-treatment and deconstruction (61-63). Interestingly, we also found that two pectinesterases (Zm00001d030622 and Zm00001d030643) are within the confidence interval of another saccharification efficiency QTL (qSACC_1_2). Pectinesterases are a group of pectinases that modify pectins during cell wall development and can consequently affect the cell wall architecture (64). 
On the other hand, lignin has been pointed out as the most important polymer in the determination of biomass recalcitrance (65). This role has led to the identification of the genes involved in monolignol biosynthesis and polymerization, as well as the transcription factors that regulate lignin synthesis. The maize MYBs are classified into 37 groups (66), according to their phylogeny, expression patterns, and also structural and functional characteristics. In our association study, we identified two genes encoding MYB tf probably involved in the phenylpropanoid pathway that lie within the confidence intervals of QTL for saccharification efficiency (qSACC_1_2 and qSACC_6_1): MYB 100 (Zm00001d030644), clustered in G13 "metabolism" and MYB 130 (Zm00001d038930) in G28

"phenylpropanoid pathway". A branch of the phenylpropanoid pathway leads to the synthesis of phenolic precursors and monomers of lignin; and the other branch to flavonoids, stilbenes and coumarins. The closest Arabidopsis ortholog of MYB 130 is a gene involved in anthocyanin metabolism. As suggested by Barrière et al. (67), MYB 130 may not be directly involved in biosynthesis of lignified cell walls; still it could be indirectly involved in phenylpropanoid pathway through regulation of other compounds $(66,67)$. Among Arabidopsis ortholog genes of maize MYB 100 classified in the same group, AtMYB61 was shown to participate in Arabidopsis lignin biosynthesis $(68,69)$, and it produced ectopic lignification when over-expressed in Arabidopsis plants, besides being involved in establishing the xylem to phloem ratio during secondary growth (68). Another ortholog, HvMYB33, is expressed in lignifying tissue of barley (70); meanwhile AtMYB 50, AtMYB 55 and AtMYB 86 may be also involved in regulating secondary cell wall biosynthesis (71).

In the phenylpropanoid pathway that leads to the synthesis of lignin monolignols, Coumaroyl-CoA is converted into caffeoyl-CoA through the formation of quinate or shikimate esters by a hydroxycinnamoyl transferase (HCT) (72). Here, we found a gene encoding a hydroxycinnamoyl transferase (Zm00001d030542) that lies within the confidence interval for the saccharification efficiency QTL in chromosome 1 (qSACC_1_1). The downregulation of this enzyme has been shown to change lignin composition by enriching $\mathrm{H}$ units and decreasing the S:G ratio (73-75). Increases in $\mathrm{H}$ produce a greater frequency of resistant inter-unit bonds, and this strengthening of the cell wall leads to less amenability and degradability (76-78). Therefore, gene Zm00001d030542 appears as a promising candidate gene for improving saccharification efficiency.

Finally, cell wall composition and organisation is a remarkably polygenic character and is influenced by hormonal and developmental factors. Interestingly, we found a gene encoding a Gibbellerin 2-oxidase (Zm00001d038996), which irreversibly catalyzes the deactivation of bioactive gibbellerin, within the confidence interval of the saccharification efficiency QTL qSACC_6_1. Gibberellic acid (GA) has been shown to regulate lignin biosynthesis and morphogenesis, at higher amounts of bioactive GA, levels of lignification in plant tissues are increased suggesting that lignification and biomass recalcitrance could be optimized by targeting gibberellin biosynthesis (79).

\section{Conclusion}

In order to develop materials with higher biofuel yield per hectare we highlight in the current study genomic regions directly linked to stover yield and saccharification efficiency. Markers located in those regions that can be used in assisted-selection programs. The candidate genes identified in this study, support that total lignin and lignin composition play an important role in cell wall recalcitrance. Meanwhile genes involved in nitrogen assimilation, organ growth, and stress tolerance are potential candidates to improve stover production. This study opens a possible optimisation path for improving the viability of second generation biofuels.

\section{Material And Methods Plant Material}

The founders of the MAGIC population were the inbred lines EP17, EP43, EP53, PB60, PB130, F473, A509, and EP125. Procedures used to release the 672 recombinant inbred lines of the population have been previously reported $(41,80)$.

\section{Experimental Design}

A subset of 408 RILs of the MAGIC population together with the eight founders included as checks were tested in a single augmented design with 10 blocks in Pontevedra, Spain (42 24' $\mathrm{N}, 8^{\circ} 38^{\prime} \mathrm{W}$ and $20 \mathrm{~m}$ above sea level), in two years (2016 and 2017). Forty-two non replicated RILs plus eight checks (the founder PB130 was replaced by EC212 in 2017 and the founder EP43 was replaced by EP80 in both years due to lack of seed availability) were randomly assigned to each block. Only 30 RILs were evaluated in block 10 . Each 
experimental plot consisted of a single row with 13 single-kernel hills planted manually, spacing between consecutive hills in a row being $0.18 \mathrm{~m}$ and $0.8 \mathrm{~m}$ between rows, obtaining a final density of $\sim 70,000$ plants ha ${ }^{-1}$. Local agronomical practices were fulfilled.

\section{Stover Yield And Saccharification Determinations}

Plots were harvested approximately 55 days after silking (days from planting until half of the plants in the plot showed visible silks). In each plot, the weight of plants without ears (weight of fresh stover) was recorded, and a stover sample was collected for estimating the percentage of stover dry matter and carry out the saccharification efficiency analyses. The stover sample was composed of tissue from two to ten plants, the fresh stover was weighed (sample fresh weight), chopped, pre-dried at $35^{\circ} \mathrm{C}$ in a forced air camera, dried at $60{ }^{\circ} \mathrm{C}$ in a stove and again weighed (sample dry weight). Dry stove samples from each plot were grounded in a Wiley mill with a $0.75 \mathrm{~mm}$ screen for saccharification assays.

Stover yield in $\mathrm{Mg} \mathrm{ha}^{-1}$ was determined by the following equation:

Saccharification assays were performed as described in Gomez et al. (81). Ground material was weighed into 96-well plates, each well contained $4 \mathrm{mg}$ of each sample either as four replicates; and processed using a high-throughput automated system (Tecan). Samples were pre-treated with $0.5 \mathrm{M} \mathrm{NaOH}$ at $90^{\circ} \mathrm{C}$ for $30 \mathrm{~min}$, washed four times with $500 \mu$ l sodium acetate buffer and finally subjected to enzymatic digestion (Celluclast 2, 7FPU/g) at $50^{\circ} \mathrm{C}$ for 9 hours. The amount of released sugars was assessed against a glucose standard curve using the 3-methyl-2-benzothiazolinone hydrozone method.

\section{Statistical Analysis}

Inbred lines were previously genotyped using a genotyping-by-sequencing (GBS) strategy for 955,690 SNPs (82). Genotypic and phenotypic datasets were combined. The SNPs with more than $50 \%$ missing data and a minor allele frequency less than $5 \%$ were omitted. Heterozygous genotypes were considered missing data. After filtering, 215.131 SNPs distributed across the maize genome were retained.

Each trial was analyzed separately and combined according to the mixed model procedure (PROC MIXED) of the SAS program (version 9.4) (83) and the best linear unbiased estimator for each inbred line was calculated based on the combined data for the 2-year analysis. Lines were considered as fixed effects, while years and blocks within years were treated as random effects. The comparison of means was carried out using the Fisher's protected least significant difference (LSD).

A genome-wide association analysis was completed with Tassel 5 (84) based on a mixed linear model using a genotype-phenotype matrix and a kinship matrix obtained by the centered identity by state (IBS) method (85). Among the mixed linear model options, we used the optimum compression level and P3D to estimate the variance components.

\section{Snps, Qtl And Candidate Gene Selection}

A Bonferroni approach was used to calculate the comparison-wise threshold for declaring significant an association between a trait and a SNP; the experiment-wise threshold (0.3) was divided by the number of independent tests (12397 independent comparisons) (86). We used Haploview program to generate independent blocks using the option four gamete rules $(87,88)$. We considered a $+/-700$ $\mathrm{kbp}$ confident interval region around each significant SNP following previous association studies using the same mapping population (40). In case confidence intervals of two SNPs overlapped they were assigned to a single QTL. The two described genes that delimit the +/-700 kbp region around the SNP in the reference genome assembly version 2 were positioned in version 4 of the reference genome, and all genes contained in the region delimited by those genes were then identified and characterized based on the maize B73 reference genome assembly (version 4) available on the MaizeGDB browser (89) (Supplementary Table 1).

\section{Abbreviations}

MAGIC

Multi-Parent Advanced Generetion InterCross

GWAS

Genome Wide Association

Page 10/16 
SNP

Single Nucleotide Polymorphism

QTL

Quantitative Trait Loci

SACC

Saccharification efficiency

RIL

Recombinant Inbred Line

HCT

Hydroxycinnamoyl transferase

ROS

Reactive Oxygen Species

GST

Glutathione S-transferase

ARGOS

Auxin-regulated Genes involved in Organ Size

HG

Homogalacturan

\section{Declarations}

\section{Ethics approval and consent to participate}

Not applicable in this study.

\section{Consent for publication}

Not applicable in this study.

\section{Availability of data and materials}

The data sets used and/or analysed during the current study will be available upon reasonable request to the corresponding author. Vegetal materials are distributed to the scientific community by Maize Genetics and Breeding group of MBG-CSIC upon request (http://www.mbg.csic.es/en/plant-genetics-and-breeding-department/maize-genetics-and-breeding/. RA Malvar, rmalvar@mbg.csic.es)

\section{Competing interests}

The authors declare that they have no competing interests.

\section{Funding}

This research has been developed in the frame of the 'Agri-Food Research and Transfer Centre of the Water Campus (CITACA) at the University of Vigo (Spain), which is economically supported by the Galician Government and in the Mlsión Biológica de Galicia-CSIC. It was funded by the "Plan Estatal de Ciencia y Tecnología de España" (projects RTI2018-096776-B-C21, and RTI2018-096776-B-C22 cofinanced with European Union funds under the FEDER program). A. López-Malvar's scholarship for the PhD fulfilment has been granted by University of Vigo and by a contract charged to the project RTI2018-096776-B-C22. R. Santiago's postdoctoral contract "Ramón y Cajal" has been financed by the Ministry of Economy and Competiveness (Spain), Vigo University, and the European Social Fund. D. Figueroa-Garrido contract was funded by the project RTI2018-096776-B-C22. The funding body played no role in study design, data analysis, and manuscript preparation.

\section{Authors' contributions}

RAM, RS conceived the study. RAM, RS, AL, PR and AB participated in its design and carried out the field trial; DF and AL participated in sample collection; $A L, R A M, R S$ and $A B$ performed data analysis; $A L$ wrote the manuscript; $L F, L G$ and SMM performed laboratory analysis and assisted in saccharification efficiency determinations. All authors read and approved the final manuscript. 


\section{Acknowledgements}

We thank B. Ordás on his contribution to MAGIC development. We thank Laura Faas for technical assistance in laboratory determinations.

\section{Author details}

1 Facultad de Biología, Departamento de Biología Vegetal y Ciencias del Suelo, Universidad de Vigo, As Lagoas Marcosende, 36310 Vigo, Spain. Agrobiología Ambiental, Calidad de Suelos y Plantas (UVIGO), Unidad Asociada a la MBG (CSIC), Vigo, Spain.

2 Misión Biológica de Galicia (CSIC), Pazo de Salcedo, Carballeira 8, 36143 Pontevedra, Spain.

3 CNAP, Department of Biology, University of York, Heslington, York Y010 5YW, UK

\section{References}

1. Vermerris W, Saballos A, Ejeta G, Mosier NS, Ladisch MR, Carpita NC. Molecular breeding to enhance ethanol production from corn and sorghum stover. Crop Sci. 2007;47:S142-S153.

2. van der Weijde T, Alvim Kamei CL, Torres AF, Vermerris W, Dolstra O, Visser RGF, et al. The potential of C4 grasses for cellulosic biofuel production. Front Plant Sci. 2013;4:1-18.

3. Dhugga KS. Maize biomass yield and composition for biofuels. Crop Sci. 2007;47(6):2211-27.

4. Lorenz AJ, Coors JG, De Leon N, Wolfrum EJ, Hames BR, Sluiter AD, et al. Characterization, genetic variation, and combining ability of maize traits relevant to the production of cellulosic ethanol. Crop Sci. 2009;49(1):85-98.

5. Kadam KL, McMillan JD. Availability of corn stover as a sustainable feedstock for bioethanol production. Bioresour Technol. 2003;88(1):17-25.

6. Graham RL, Nelson R, Sheehan J, Perlack RD, Wright LL. Current and potential U.S. corn stover supplies. Agron J. 2007;99(1):1-11.

7. Chundawat SPS, Venkatesh B, Dale BE. Effect of particle size based separation of milled corn stover on AFEX pretreatment and enzymatic digestibility. Biotechnol Bioeng. 2007;96(2):219-31.

8. Pauly M, Keegstra K. Cell-wall carbohydrates and their modification as a resource for biofuels. Plant J. 2008;54(4):559-68.

9. Mosier N, Wyman C, Dale B, Elander R, Lee YY, Holtzapple M, et al. Features of promising technologies for pretreatment of lignocellulosic biomass. Bioresour Technol. 2005;96(6):673-86.

10. Carpita NC, McCann MC. The Cell Wall. Biochem Mol Biol Plants Am Soc Plant Physiol. :52-108.

11. Santiago R, Malvar RANA, Barros-Rios J, Malvar RANA, Butrón A, Sandoya G, et al. Impact of cell wall composition on maize resistance to pests and diseases. J Agric Food Chem . 2013;54(4):2274-9.

12. Barrière $Y$, Méchin V, Riboulet $C$, Guillaumie $S$, Thomas $\mathrm{J}$, Bosio $M$, et al. Genetic and genomic approaches for improving biofuel production from maize. Euphytica. 2009;170(1):183-202.

13. Jung HG, Mertens DR, Phillips RL. Effect of reduced ferulate-mediated lignin/arabinoxylan cross-linking in corn silage on feed intake, digestibility, and milk production. J Dairy Sci . 2011;94(10):5124-37.

14. Silverstein RA, Chen Y, Sharma-Shivappa RR, Boyette MD, Osborne J. A comparison of chemical pretreatment methods for improving saccharification of cotton stalks. Bioresour Technol. 2007;98(16):3000-11.

15. Chen Y, Stevens MA, Zhu Y, Holmes J, Xu H. Understanding of alkaline pretreatment parameters for corn stover enzymatic saccharification. Fuel Prod from Non-Food Biomass Corn Stover. 2015;131-53.

16. Scalbert A, Monties B, Lallemand JY, Guittet E, Rolando C. Ether linkage between phenolic acids and lignin fractions from wheat straw. Phytochemistry. 1985;26(6):1359-62.

17. liyama K, Lam T, Stone B a. Covalent Cross-Links in the Cell Wall. Plant Physiol. 1994;104(2):315-20.

18. Lapierre $C$, Jouin D, Monties B. On the molecular origin of the alkali solubility of Gramineae lignins. Phytochemistry. 1989;28(5):1401-3.

19. Liu T, Williams DL, Pattathil S, Li M, Hahn MG, Hodge DB. Coupling alkaline pre-extraction with alkaline-oxidative post-treatment of corn stover to enhance enzymatic hydrolysis and fermentability. Biotechnol Biofuels. 2014;7(1):1-12. 
20. Barrière Y, Méchin V, Denoue D, Bauland C, Laborde J. QTL for yield, earliness, and cell wall quality traits in topcross experiments of the F838 × F286 early maize RIL progeny. Crop Sci. 2010;50(5):1761-72.

21. Hansey CN, Lorenz AJ, de Leon N. Cell wall composition and ruminant digestibility of various maize tissues across development. Bioenergy Res. 2010;3(1):28-37.

22. Pitre FE, Brereton NJB, Audoire S, Richter GM, Shield I, Karp A. Estimating root biomass in Salix viminalis $\times$ Salix schwerinii cultivar "Olof" using the electrical capacitance method. Plant Biosyst. 2010;144(2):479-83.

23. Feltus FA, Vandenbrink JP. Bioenergy grass feedstock: current options and prospects for trait improvement using emerging genetic , genomic , and systems biology toolkits. 2012;1-20.

24. Lorenzana RE, Lewis MF, Jung HJG, Bernardo R. Quantitative trait loci and trait correlations for maize stover cell wall composition and glucose release for cellulosic ethanol. Crop Sci. 2010;50(2):541-55.

25. Truntzler M, Barrière Y, Sawkins MC, Lespinasse D, Betran J, Charcosset $A$, et al. Meta-analysis of QTL involved in silage quality of maize and comparison with the position of candidate genes. Theor Appl Genet. 2010;121(8):1465-82.

26. Penning BW, Sykes RW, Babcock NC, Dugard CK, Held MA, Klimek JF, et al. Genetic Determinants for Enzymatic Digestion of Lignocellulosic Biomass Are Independent of Those for Lignin Abundance in a Maize Recombinant Inbred Population. Plant Physiol. 2014;165(4):1475-87.

27. Hsu T, Ladisch R, Tsao G. Alcohol from cellulose. Vol. 1203, Chem. Intermed. 1980. p. 3.

28. Kootstra AMJ, Beeftink HH, Scott EL, Sanders JPM. Comparison of dilute mineral and organic acid pretreatment for enzymatic hydrolysis of wheat straw. Biochem Eng J. 2009;46(2):126-31.

29. Marcotullio G, De Jong W. Chloride ions enhance furfural formation from d-xylose in dilute aqueous acidic solutions. Green Chem. 2010;12(10):1739-46.

30. Suwarno WB, Pixley K V., Palacios-Rojas N, Kaeppler SM, Babu R. Genome-wide association analysis reveals new targets for carotenoid biofortification in maize. Theor Appl Genet. 2015;128(5):851-64.

31. Zila CT, Samayoa LF, Santiago R, Butrón A, Holland JB. A Genome-Wide Association Study Reveals Genes Associated with Fusarium Ear Rot Resistance in a Maize Core Diversity Panel. G3 Genes|Genomes|Genetics . 2013;3(11):2095-104.

32. Samayoa LF, Malvar RA, Olukolu BA, Holland JB, Butrón A. Genome-wide association study reveals a set of genes associated with resistance to the Mediterranean corn borer (Sesamia nonagrioides L.) in a maize diversity panel. BMC Plant Biol . 2015;15(1):35.

33. Wang H, Li K, Hu X, Wu Y, Huang C. Genome-wide association analysis of forage quality in maize mature stalk. BMC Plant Biol. 2016;16:227.

34. Li K, Wang H, Hu X, Liu Z, Wu Y, Huang C. Genome-wide association study reveals the genetic basis of stalk cell wall components in maize. PLoS One. 2016;11(8).

35. López-Malvar A, Butrón A, Samayoa LF, Figueroa-Garrido DJ, Malvar RA, Santiago R. Genome-wide association analysis for maize stem Cell Wall-bound Hydroxycinnamates. BMC Plant Biol. 2019;19(1):1-12.

36. Myles S, Peiffer J, Brown PJ, Ersoz ES, Zhang Z, Costich DE, et al. Association mapping: Critical considerations shift from genotyping to experimental design. Plant Cell. 2009;21(8):2194-202.

37. Yan J, Warburton M, Crouch J. Association mapping for enhancing maize (Zea mays L.) genetic improvement. Crop Sci. 2011;51(2):433-49.

38. Bernardo R. Bandwagons I, too, have known. Theor Appl Genet. 2016;129(12):2323-32.

39. Jiménez-Galindo JC, Malvar RA, Butrón A, Santiago R, Samayoa LF, Caicedo M, et al. Mapping of resistance to corn borers in a MAGIC population of maize. BMC Plant Biol. 2019;19(1):1-17.

40. Yi Q, Malvar RA, Álvarez-Iglesias L, Ordás B, Revilla P. Dissecting the genetics of cold tolerance in a multiparental maize population. Theor Appl Genet. 2020;133(2):503-16.

41. Butrón Gómez AM; Santiago Carabelos R; Cao Caamaño, Ana; Samayoa López, Luis Fernando; Malvar Pintos RA. QTLs for Resistance to Fusarium Ear Rot in a Multiparent Advanced Generation Intercross (MAGIC) Maize Population. Plant Dis. 2019;103(5):897-904.

42. Marriott PE, Sibout R, Lapierre C, Fangel JU, Willats WGT, Hofte H, et al. Range of cell-wall alterations enhance saccharification in Brachypodium distachyon mutants . Proc Natl Acad Sci. 2014;111(40):14601-6.

43. Chichkova S, Arellano J, Vance CP, Hernández G. Transgenic tobacco plants that overexpress alfalfa NADH-glutamate synthase have higher carbon and nitrogen content. J Exp Bot. 2001;52(364):2079-87.

Page 13/16 
44. Hansey CN, de Leon N. Biomass yield and cell wall composition of corn with alternative morphologies planted at variable densities. Crop Sci. 2011;51(3):1005-15.

45. Vinocur B, Altman A. Recent advances in engineering plant tolerance to abiotic stress: Achievements and limitations. Curr Opin Biotechnol. 2005;16(2):123-32.

46. Umezawa T, Fujita M, Fujita Y, Yamaguchi-Shinozaki K, Shinozaki K. Engineering drought tolerance in plants: discovering and tailoring genes to unlock the future. Curr Opin Biotechnol. 2006;17(2):113-22.

47. Sakamoto T, Matsuoka M. Generating high-yielding varieties by genetic manipulation of plant architecture. Curr Opin Biotechnol. 2004;15(2):144-7.

48. Frova C. The plant glutathione transferase gene family: Genomic structure, functions, expression and evolution. Physiol Plant. 2003;119(4):469-79.

49. Dixon DP, Lapthorn A, Edwards R. Protein family review Plant glutathione transferases. 2002;1-10.

50. Cushman JC, Bohnert HJ. Genomic approaches to plant stress tolerance. Curr Opin Plant Biol. 2000;3(2):117-24.

51. Busov VB, Brunner AM, Strauss SH. Genes for control of plant stature and form. New Phytol. 2008;177(3):589-607.

52. Krizek BA. Making bigger plants: key regulators of final organ size. Curr Opin Plant Biol. 2009;12(1):17-22.

53. Gonzalez N, Beemster GT, Inzé D. David and Goliath: what can the tiny weed Arabidopsis teach us to improve biomass production in crops? Curr Opin Plant Biol. 2009;12(2):157-64.

54. Guo M, Rupe MA, Wei J, Winkler C, Goncalves-Butruille M, Weers BP, et al. Maize ARGOS1 (ZAR1) transgenic alleles increase hybrid maize yield. J Exp Bot. 2014;65(1):249-60.

55. Anna N. Stepanova, Hoyt JM, Hamilton AA, Alonso JM. A Link between Ethylene and Auxin Uncovered by the Characterization of Two Root-Specific Ethylene-Insensitive Mutants in Arabidopsis. Plant Cell. 2005;17:2230-2242.

56. Yingqing LU, LI N, XIE L, Wang Y, Zhang R, Chen J. Anthranilate synthase allele fragments for increasing rice yield and uses thereof. 2018.

57. Man H, Pollmann S, Weiler EW, Kirby EG. Increased glutamine in leaves of poplar transgenic with pine GS1a caused greater anthranilate synthetase a-subunit (ASA1) transcript and protein abundances: An auxin-related mechanism for enhanced growth in GS transgenics? J Exp Bot. 2011;62(13):4423-31.

58. Xiao C, Anderson CT. Roles of pectin in biomass yield and processing for biofuels. Front Plant Sci. 2013;4:1-7.

59. Latarullo MBG, Tavares EQP, Maldonado GP, Leite DCC, Buckeridge MS. Pectins, endopolygalacturonases, and bioenergy. Front Plant Sci. 2016;7:1-7.

60. Kostylev M, Wilson D. Synergistic interactions in cellulose hydrolysis. Biofuels. 2012;3(1):61-70.

61. Biswal AK, Atmodjo MA, Li M, Baxter HL, Yoo CG, Pu Y, et al. Sugar release and growth of biofuel crops are improved by downregulation of pectin biosynthesis. Nat Biotechnol. 2018;36(3):249-57.

62. Lionetti V, Francocci F, Ferrari S, Volpi C, Bellincampi D, Galletti R, et al. Engineering the cell wall by reducing de-methyl-esterified homogalacturonan improves saccharification of plant tissues for bioconversion. Proc Natl Acad Sci U S A. 2010;107(2):616-21.

63. Li M, Yoo CG, Pu Y, Biswal AK, Tolbert AK, Mohnen D, et al. Downregulation of pectin biosynthesis gene GAUT4 leads to reduced ferulate and lignin-carbohydrate cross-linking in switchgrass. Commun Biol. 2019;2(1):1-11.

64. Jayani RS, Saxena S, Gupta R. Microbial pectinolytic enzymes: A review. Process Biochem. 2005;40(9):2931-44.

65. Weng J, Li X, Bonawitz ND, Chapple C. Emerging strategies of lignin engineering and degradation for cellulosic biofuel production. 2008; 19(2):166-72

66. Du H, Feng BR, Yang SS, Huang YB, Tang YX. The R2R3-MYB transcription factor gene family in maize. PLoS One. 2012;7(6):1-12.

67. Barrière Y, Courtial A, Soler M, Grima-Pettenati J. Toward the identification of genes underlying maize QTLs for lignin content, focusing on colocalizations with lignin biosynthetic genes and their regulatory MYB and NAC transcription factors. Mol Breed. 2015;35(3).

68. Newman LJ, Perazza DE, Juda L, Campbell MM. Involvement of the R2R3-MYB, AtMYB61, in the ectopic lignification and darkphotomorphogenic components of the det3 mutant phenotype. Plant J. 2004;37(2):239-50.

69. Dubos C, Stracke R, Grotewold E, Weisshaar B, Martin C, Lepiniec L. MYB transcription factors in Arabidopsis. Trends Plant Sci. 2010;15(10):573-81. 
70. Wissenbach M, Überlacker B, Vogt F, Becker D, Salamini F, Ronde W. Myb genes from Hordeum vulgare: Tissue-specific expression of chimeric Myb promoter/GUS genes in transgenic tobacco. Vol. 4, Plant Journal. 1993. p. 411-22.

71. Cai H, Chu Q, Gu R, Yuan L, Liu J, Zhang X, et al. Identification of QTLs for plant height, ear height and grain yield in maize (Zea mays L.) in response to nitrogen and phosphorus supply. Plant Breed. 2012;131(4):502-10.

72. Boerjan W, Ralph J, Baucher M. Lignin Biosynthesis. Annu Rev Plant Biol . 2003;54(1):519-46.

73. Hoffmann L, Besseau S, Geoffroy P, Ritzenthaler C, Meyer D, Lapierre C, et al. Silencing of Hydroxycinnamoyl-Coenzyme A Shikimate/Quinate Hydroxycinnamoyltransferase Affects Phenylpropanoid Biosynthesis. Plant Cell. 2004;16:1446-1465.

74. de Souza WR, Martins PK, Freeman J, Pellny TK, Michaelson L V., Sampaio BL, et al. Suppression of a single BAHD gene in Setaria viridis causes large, stable decreases in cell wall feruloylation and increases biomass digestibility. New Phytol. 2018;218(1):81-93.

75. John Ralph, Akiyama T, Kim H, Lu F, Schatz PF, Marita JM, et al. Effects of Coumarate 3-Hydroxylase Down-regulation on Lignin Structure. J Biol Chem. 2006;28(13):8843-8853.

76. Riboulet $C$, Lefèvre $B$, Dénoue $D$, Barrière $Y$. Genetic variation in maize cell wall for lignin content, lignin structure, phydroxycinnamic acid content, and digestibility in set of 19 lines at silage harvest maturity. Maydica. 2008;53(1):11-9.

77. Cabane M, Afif D, Hawkins S. Lignins and Abiotic Stresses . 1st ed. Vol. 61, Advances in Botanical Research. Elsevier Ltd.; 2012. 219-262 p.

78. Barrière Y, Riboulet $C$, Méchin V, Maltese S, Pichon M, Cardinal A, et al. Genetics and genomics of lignification in grass cell walls based on maize as model species. Genes Genomes Genomics. 2007;1:133-56.

79. Wuddineh WA, Mazarei M, Zhang J, Poovaiah CR, Mann DGJ, Ziebell A, et al. Identification and overexpression of gibberellin 2oxidase (GA2ox) in switchgrass (Panicum virgatum L.) for improved plant architecture and reduced biomass recalcitrance. Plant Biotechnol J. 2015;13(5):636-47.

80. Jiménez-Galindo JC, Ordás B, Butrón A, Samayoa LF, Malvar RA. QTL Mapping for Yield and Resistance against Mediterranean Corn Borer in Maize. Front Plant Sci . 2017;8:2-11.

81. Gomez LD, Whitehead C, Barakate A, Halpin C, McQueen-Mason SJ. Automated saccharification assay for determination of digestibility in plant materials. Biotechnol Biofuels . 2010;3(1):23.

82. Jiménez-Galindo JC. Regiones genómicas asociadas a la resistencia a insectos y al rendimiento en maíz. PhD Thesis, Universidad de Santiago de Compostela, Spain; 2017.

83. SAS/STAT; SAS Institute Inc.: Cary, NC, 2007.

84. Bradbury PJ, Zhang Z, Kroon DE, Casstevens TM, Ramdoss Y, Buckler ES. TASSEL: Software for association mapping of complex traits in diverse samples. Bioinformatics. 2007;23(19):2633-5.

85. Olukolu BA, Negeri A, Dhawan R, Venkata BP, Sharma P, Garg A, et al. A connected set of genes associated with programmed cell death implicated in controlling the hypersensitive response in maize. Genetics. 2013;193(2):609-20.

86. Li J, Ji L. Adjusting multiple testing in multilocus analyses using the eigenvalues of a correlation matrix. Heredity (Edinb). 2005;95(3):221-7.

87. Barrett JC, Fry B, Maller J, Daly MJ. Haploview: Analysis and visualization of LD and haplotype maps. Bioinformatics. 2005;21(2):263-5.

88. Wang N, Akey JM, Zhang K, Chakraborty R, Jin L. Distribution of recombination crossovers and the origin of haplotype blocks: The interplay of population history, recombination, and mutation. Am J Hum Genet. 2002;71(5):1227-34.

89. Andorf C, Cannon E, Portwood J, Gardiner J, Harper L, Schaeffer M, et al. MaizeGDB update: new tools, data and interface for the maize model organism database. Nucleic acids research. 2015.

\section{Supplementary Files Legend}

Supplementary Table 1: Complete list of candidate genes for QTLs found for saccharification efficiency and stover yield in a MAGIC population.

\section{Supplementary Files}

This is a list of supplementary files associated with this preprint. Click to download.

Page 15/16 
- SuplemmentarytableGENELIST1RS.docx

Page 16/16 